\title{
Alexitimia: Dificuldade de Expressão ou Ausência de Sentimento? Uma Análise Teórica
}

\author{
Luís Freire ${ }^{1}$ \\ Universidade Estadual de Feira de Santana
}

\begin{abstract}
RESUMO - O objetivo deste ensaio é apresentar uma base conceitual para diferenciar emoções de sentimentos, a partir das ideias de LeDoux e Damásio, e usar essa base numa abordagem sobre o conceito e as origens da alexitimia, constructo recentemente desenvolvido para retratar a dificuldade de expressar emoções e sentimentos. Nessa abordagem, é questionado se o alexitímico não expressa ou não tem sentimentos. A conclusão deste ensaio é que no alexitímico as emoções ocorrem normalmente, mas os sentimentos, que requerem circuitos cerebrais adicionais em relação aos acionados pelas emoções, não são desenvolvidos de forma adequada. São apresentadas as limitações do trabalho e sugestões para um programa de pesquisa.
\end{abstract}

Palavras-chave: emoção; cognição; regulação emocional LeDoux; Damásio.

\section{Alexithymia: Difficulty of Expression or Absence of Feeling? A Theoretical Analysis}

\begin{abstract}
The aim of this essay is to present a conceptual basis to differentiate emotions from feelings, based on LeDoux and Damasio's ideas, and to use this basis for an approach to Alexithymia's concept and origins, a construct recently developed to explain the difficulty of expressing emotions and feelings. In this approach, it is questioned whether alexithymic individuals do not express or do not have feelings. The conclusion of this essay is that emotions occur normally in alexithymic individuals, but that feelings, which require additional brain circuits in relation to those driven by emotions, are not developed properly. Limitations of this work and suggestions for a research program are presented.
\end{abstract}

Keywords: emotions; cognition; emotional regulation; LeDoux; Damasio.

Emoção e sentimentos são duas palavras bem conhecidas e usadas em nosso dia a dia, mas cuja distinção e conceituação ainda são bastante confusas, mesmo entre especialistas. Por exemplo, Gazzaniga e Heatherton (2003/2005), num texto didático, definem emoção como sendo sentimento: " a emoção se refere a sentimentos que envolvem avaliação subjetiva, processos psicológicos e crenças cognitivas" ( $\mathrm{p}$. 315). A expressão de emoções e sentimentos também é algo que apresenta variação entre os seres humanos: desde uma grande facilidade até uma grande dificuldade. A dificuldade de expressar emoções foi recentemente conceituada como alexitimia (Sifneos, 1973).

Buscando apoio nos trabalhos de Joseph LeDoux e Antonio Damásio, o objetivo deste artigo, de natureza teórica, é apresentar uma base conceitual para diferenciar emoções de sentimentos, e usar essa base para explicar a alexitimia. $\mathrm{Na}$ primeira seção, os conceitos de emoções e sentimentos serão discutidos, de forma a estabelecer as diferenças entre eles. $\mathrm{Na}$ segunda seção, a alexitimia será apresentada e discutida à luz desses conceitos, inclusive quanto à sua origem, de tal forma que se possa responder se o alexitímico não tem emoções

1 Endereço para correspondência: Universidade Estadual de Feira de Santana, Departamento de Ciencias Sociais-DCIS. Av. Transnordestina, s/n, Bairro Novo Horizonte. Feira de Santana, BA. CEP 44.036-900. E-mail: 1c.freire@terra.com.br. ou não tem a percepção delas, não as sente conscientemente, impedindo a geração do sentimento correspondente. $\mathrm{O}$ artigo é encerrado com algumas reflexões pessoais.

\section{Emoção e Sentimento}

No cérebro humano não existe um sistema único dedicado à emoção. Rose (2005/2006) diz que buscar a localização da emoção em alguma área especifica do cérebro é cometer um "erro de categoria", porque os processos emocionais "são feitos não em uma localização, mas em um padrão de interações dinâmicas entre regiões múltiplas do cérebro" (p. 226). Para LeDoux (1996/1998), as várias classes de emoções são mediadas por sistemas neurais distintos, os quais evoluíram para resolver diferentes problemas que os animais enfrentam em sua vida diária: "não existe a faculdade da emoção, e tampouco existe um sistema cerebral único encarregado dessa função fantasma" (p. 16). E Damásio (1999/2000) diz: "não existe um único centro cerebral de processamento das emoções, e sim sistemas distintos relacionados a padrões emocionais separados" (p. 88).

Mas emoção é um conceito bastante complexo. LeDoux $(2000,2007)$ afirma que a diversidade de conceitos tem sido um grande obstáculo para a pesquisa e o entendimento das emoções. Apesar do crescimento no número de pesquisas nos 
últimos anos dedicadas à emoção, os pesquisadores têm se amparado em diferentes orientações teóricas para a definição do construto. Se há algum consenso, com certeza é sobre a dificuldade de defini-la. Kleinginna e Kleinginna (1981), ao avaliarem o uso do conceito na literatura, encontraram 92 definições e nove afirmações "céticas", as quais foram separadas em 11 categorias, além de alguns autores que colocam em dúvida a utilidade de se tentar definir emoção.

Alguns autores percebem a emoção como um fenômeno diretamente observável, de natureza consciente (Baumeister, Vohs, DeWall, \& Zhang, 2007), e fundamentado em experiências aprendidas e incorporadas, como na percepção das cores (Barrett, 2006). Outros veem as emoções como tendo tanto um componente biofisiológico, portanto involuntário e quase sempre inconsciente, quanto um componente experiencial-cognitivo, que pode ser inconsciente, mas que na maioria das vezes é consciente, operando em diferentes níveis (Panksepp, 2008). Todavia, qual a diferença entre a emoção inconsciente, que "nos acontece" e a emoção consciente, sobre a qual temos algum poder?

Para LeDoux (2007) e Damásio (1994/1996, 1999/2000), a emoção consciente já não é mais apenas emoção, mas sentimento. Eles distinguem esses dois fenômenos, considerando-os como construtos próprios e distintos, eliciados no organismo humano a partir de diferentes circuitos cerebrais. A abordagem de LeDoux será apresentada em seguida, a partir de uma crítica por ele desenvolvida sobre uma proposta de Scherer (2005). E, logo depois, a proposta de Damásio será também apresentada.

\section{A crítica de Joseph LeDoux à proposta de Klaus Scherer}

Scherer (2005) sugere a existência de cinco componentes para um estado emocional, os quais são acionados por determinados sistemas corporais responsáveis por diferentes processos funcionais. Os cinco componentes sugeridos são: cognição, sintomas físicos (componentes neurológicos), motivação, expressão motora e a experiência subjetiva ou sentimento.

O componente cognitivo da emoção é acionado pelo Sistema Nervoso Central (SNC) e sua função é a avaliação de objetos e eventos que se manifestam no mundo externo O componente neurofisiológico, acionado pelo SNC, Sistema Neuro-Endócrino (SNE) e Sistema Nervoso Autônomo (SNA), tem como função a regulação do organismo. O componente motivacional, também acionado pelo SNC, tem como função a preparação e direção das ações que serão desencadeadas. O componente da expressão motora corresponde às ações desencadeadas por meio do Sistema Nervoso Somático (SNS) e sua função é manifestar a reação e sua correspondente intenção. O último componente é a experiência subjetiva, ou sentimento, acionado também pelo SNC, cuja função é o monitoramento do estado do organismo em face de sua interação com os eventos e objetos do mundo externo.

Segundo esse esquema conceitual proposto por Scherer (2005), o sentimento é um dos componentes (a experiência subjetiva) da emoção e as emoções resultam de um episódio de alterações sincronizadas e inter-relacionadas no estado de todos ou na maior parte de cinco subsistemas do organismo, em resposta a estímulos avaliados pelo indivíduo como tendo algum significado relevante. É esse significado que elicia a emoção, a qual será mais ou menos intensa de acordo com o nível de relevância atribuído ao evento. $\mathrm{O}$ evento estimulante pode ser externo (e.g., o comportamento de outra pessoa, a visão de uma cobra), que adquire algum significado para o bem-estar da pessoa; ou pode ser interno, quando o comportamento da própria pessoa pode ser o evento eliciador da emoção (e.g., culpa, orgulho ou vergonha). Nesse esquema, as emoções são agrupadas em categorias funcionais, as quais envolvem determinado conjunto de subsistemas.

O artigo de Scherer foi apresentado na edição de dez/2005 do Social Science Information. A edição de set/2007 desse mesmo periódico traz 12 comentários sobre o artigo. De uma forma geral, todos os comentaristas concordam com os pontos fundamentais da proposta de Scherer, mas diferem na apreciação de algumas particularidades, como ocorreu com Joseph LeDoux.

LeDoux ${ }^{2}$ é um neurocientista e autor de diversos livros e artigos científicos sobre como o cérebro processa emoções. LeDoux (1996/1998, 2000) atribui o sucesso dos vários trabalhos realizados na área, inclusive os de Damásio e sua equipe, ao fato de terem o foco em aspectos da emoção psicologicamente bem definidos, evitando conceitos vagos e pobremente formulados, como afetos e sentimentos emocionais, e por usarem abordagens experimentais simples e diretas.

A principal questão levantada por LeDoux na análise da proposta de Scherer é sobre o que compõe cada subsistema e sua função respectiva. Ele diz:

A abordagem de componente-processo é uma excelente forma
para conceituar os vários processos que ocorrem durante uma
emoção. Nesse esquema, uma emoção é o resultado que surge
da atividade combinada de uma variedade de subsistemas. Mas
eu discordo de Scherer em como conceituar os subsistemas. Eu
não estou convencido que os cinco subsistemas identificados
constituam um grupo de subsistemas reais e criticos do orga-
nismo. (LeDoux, 2007, p. 399)

LeDoux (2007) cita pesquisas realizadas por ele e outros, com humanos e com não humanos, cujos resultados sugerem que, em geral, as emoções são eliciadas por meio de circuitos de localização subcortical. O desenvolvimento de ferramentas não invasivas, que trabalham com imagens, tem permitido o mapeamento do cérebro em plena atividade, mostrando que diferentes circuitos existem para diferentes funções emocionais, como as que levam à defesa frente a predadores, reprodução sexual, nutrição, ligação afetiva e afiliação ou relação parental. Conforme LeDoux, esses estudos têm mostrado a importância da amígdala e do sistema nervoso autônomo para o processamento de estímulos emocionais na ausência de uma percepção consciente do estímulo, indicando a natureza autônoma e inconsciente das emoções.

Para que as pessoas se tornem conscientes de suas emoções, diferentes regiões do cérebro necessitam ser acionadas adicionalmente, em especial áreas do córtex pré-frontal,

2 Professor de Neurociência e Psicologia e diretor do Centro para Ciência Neural da New York University. 
associadas com a cognição. Ainda conforme LeDoux (2007), outros estudos realizados com humanos têm indicado que, em geral, o processamento consciente, tanto de estímulos emocionais quanto de não emocionais, requer que o estímulo seja representado nessas áreas pré-frontais, as quais estão envolvidas com a "memória de trabalho". Esclarecendo que sua noção de memória de trabalho é ampliada, para nela incluir várias funções executivas e de monitoramento, LeDoux afirma que esses estudos sugerem que a ativação de áreas corticais pré-frontais envolvidas na memória de trabalho são a chave para a existência de emoções conscientes. Emoções conscientes são chamadas por LeDoux de sentimentos.

Todavia, LeDoux (2007) pergunta se a consciência de um estímulo emocional (que inclui tanto o estímulo específico quanto o contexto social e físico em que ambos - sujeito e estímulo - estão inseridos) é suficiente para gerar o sentimento. Em sua resposta, ele considera a necessidade de dois ingredientes adicionais. O primeiro é o significado das sensações geradas pelo estímulo emocional, obtido a partir da memória episódica e semântica do estímulo. O segundo ingrediente adicional deve ser a informação sobre o despertar emocional ou excitação do organismo, realizado pelo estímulo por meio do cérebro, como órgão receptivo às relações do organismo com o ambiente. Essa informação é obtida a partir da percepção do estado do corpo (de excitação ou relaxamento neurocortical e do sistema motor) na resposta emocional. Dito de outra forma, o sentimento requer a existência de três componentes processuais de natureza cognitiva, eliciados pela emoção: a representação do estímulo emocional na memória de trabalho, a recuperação de significados associados a esse estímulo e a percepção consciente de estados do corpo.

LeDoux $(2000,2007)$ enfatiza a diferença entre processo cognitivo e processo emocional, sublinhando que cada um desses processos aciona diferentes sistemas com distintas arquiteturas neurais. Enquanto a cognição usa processos de alto nível, mediados pelo córtex pré-frontal mais desenvolvido no ser humano, a emoção utiliza principalmente processos subcorticais, os quais automaticamente detectam e respondem aos estímulos emocionais, comuns aos humanos e não humanos. Ao encerrar seu artigo, LeDoux diz que precisamos estar alerta para essas diferenças, para evitar a confusão semântica entre processos emocionais e processos cognitivos. Ele assim se expressa:

A confusão semântica reflete algumas diferenças fundamentais no processamento emocional, que precisamos ter em mente: o processamento subcortical automático realizado por sistemas evolucionariamente programados é diferente do processamento que ocorre nas áreas pré-frontais, as quais avaliam (consciente ou inconscientemente) a situação à luz do contexto e situações externas, as memórias episódicas e semânticas, e os sinais emocionais dentro do corpo e do cérebro. (LeDoux, 2007, p. 402)

Dessa forma, existe uma diferença fundamental entre ter emoções (processo subcortical) e ter a consciência delas, ou senti-las conscientemente (processo cognitivo mediado pelo córtex pré-frontal). Se conscientizar a emoção é a condição que distingue o sentimento, este não é apenas uma etapa ou apêndice da emoção, como sugere Scherer (2005). Ainda que a manifestação do sentimento acione determinados processos que também ocorrem com as emoções, ele, o sentimento, necessita da ativação de outros componentes processuais do organismo humano, de natureza diferente dos que são acionados quando ocorre a emoção (os processos cognitivos), constituindo-se assim um fenômeno com características próprias e específicas. Essa abordagem encontra ressonância nos argumentos de Damásio, apresentados no próximo item.

\section{A proposta de António Damásio}

Damásio ${ }^{3}$ é um líder em neurociências reconhecido internacionalmente. Seus interesses de pesquisa incidem sobre o papel das emoções nas ações conscientes e inconscientes, resultando em trabalhos que têm ajudado a elucidar as bases neurais da emoção e sentimentos, mostrando que eles desempenham papéis centrais nos processos decisórios e na cognição social (1994/1996, 1999/2000) .

Damásio (1999/2000) diz que definir emoção não é uma tarefa fácil: "depois de fazer o levantamento de todo o espectro de fenômenos possíveis, ficamos imaginando se é realmente exequível formular alguma definição sensata de emoções e se um termo único ainda é útil para designar todos esses estados" (p. 430) . Apesar disso, esse autor propõe "uma hipótese de trabalho": "emoção é uma coleção de respostas químicas e neurais que formam um padrão distinto" (p. 74/430). Essas respostas constituem um "padrão distinto" porque emoções diferentes são produzidas por sistemas cerebrais diferentes, a maioria dos quais localizados nos núcleos subcorticais do tronco cerebral, da amígdala, do hipotálamo e do prosencéfalo basal, não acessíveis à consciência.

Para Damásio (1995, 1994/1996, 1999/2000), as emoções são quantificáveis (as respostas químicas e neurais) e observáveis na pessoa "emocionada", por uma terceira pessoa: expressão facial, ritmo e movimento do corpo, sudorese etc. Sentimentos são resultados da percepção dessas reações pela própria pessoa: ela "sente" a emoção. São, portanto, experiências subjetivas, somente accessíveis à própria pessoa. Essa abordagem admite que existe uma sequência no processo de geração de emoções e sentimentos. Primeiro, a percepção de um evento ou objeto pelo organismo, a qual aciona automaticamente determinados circuitos subcorticais que provocam alterações no corpo e no próprio cérebro em resposta à percepção (moléculas químicas e sinais eletroquímicos), predispondo o organismo para determinados comportamentos: isso é a emoção. Por último, as alterações sofridas pelo corpo acionam outros circuitos cerebrais, tornando-se conscientes para a pessoa: isso é o sentimento.

Essa sequência pode também ser vista no que Damásio (1999/2000) chama de continuum funcional: num extremo estão as emoções, como estados corporais inconscientes; no outro extremo estão os sentimentos, estados mentais conscientes, passando por um estágio intermediário que, na falta de outra palavra, ele chama de sentimento inconsciente. Para esse autor, "a natureza relativamente pública das emoções e a total privacidade dos sentimentos decorrentes, indicam

3 Diretor do Instituto do Cérebro e Criatividade e professor de Neurociência e Psicologia na University of Southern Califórnia. 
que os mecanismos envolvidos ao longo do continuum são muito diferentes" (p. 63-64).

$\mathrm{Na}$ abordagem de Damásio, é possível identificar dois componentes na emoção humana: um componente físico e um componente mental. Isso leva à compreensão que a emoção, enquanto processo físico tem uma manifestação física, e que esse processo pode ser acompanhado de uma sensação e de uma percepção, não dos processos em si, mas do estado global do organismo (uma imagem mental do organismo) quando esses processos ocorrem: uma palpitação cardíaca elicia a sensação de um susto; a visão de um "por do sol" elicia uma sensação de paz e relaxamento.

Essas sensações são sentimentos, primariamente inconscientes, que os humanos partilham com alguns animais. É a percepção consciente, e o cultivo desse estado do organismo, que irá gerar e desenvolver ${ }^{4}$ o sentimento consciente. Essa conscientização e cultivo só é possível em seres humanos, porque requer dispositivos cerebrais e mentais somente bem desenvolvidos em organismos humanos. Damásio (1999/2000, p. 111) diz:

Supondo que todas as estruturas apropriadas estejam no seu lugar, (esses) processos permitem a um organismo ter uma emoção, manifestá-la e transformá-la em imagem, ou seja, sentir a emoção...(Todavia), para um organismo saber que tem um sentimento é necessário acrescentar o processo da consciência.

Assim, as abordagens de LeDoux (2007) e Damásio (1994/1996, 1999/2000), discutidas até aqui, podem ser resumidas e integradas para os objetivos deste trabalho, conforme a seguir:

- Emoções podem ser compreendidas como uma combinação de ativação neurocortical (sistema nervoso autônomo e ativação neuroendócrina), expressão motora (expressão facial e vocal, postura e gesticulação) e uma sensação subjetiva inconsciente desse estado corporal, que Damásio (2004) chama de sentimento inconsciente. Esses fenômenos ocorrem de forma autônoma e inconsciente em diferentes circuitos cerebrais, a depender do tipo de emoção eliciada;

- A espécie humana dispõe de áreas cerebrais que nela são mais desenvolvidas do que em outras espécies, também usadas nas respostas emocionais: as áreas associadas ao córtex pré-frontal, responsáveis pela cognição. Essas áreas são usadas pelo indivíduo para tomar consciência da emoção por meio de sua representação imagética, a qual permite a regulação emocional e contribui para que a pessoa tenha uma vida mais bem adaptada ao ambiente. Essa "tomada de consciência" cria o sentimento: um processo cognitivo sobre as sensações subjetivas dos estados corporais (emoções) eliciados por agentes externos ou internos à pessoa, que pode vir a ser cultivado, ou não, por ela.

4 A ideia do cultivo do sentimento, para seu desenvolvimento, é acrescentada pelo autor deste trabalho. Isso significa consolidar os circuitos neurais correspondentes, pela sua repetição. Nesses termos, desenvolver sentimentos pode ser comparado a um processo de aprendizagem.
Dito de outra forma, para que haja sentimento, é necessário que o processo do circuito neural emocional vá um passo além. É necessário que haja uma passagem, uma sequência entre as áreas subcorticais responsáveis pela emoção, e as áreas corticais pré-frontais, responsáveis pela cognição, para que a pessoa crie sentimentos conscientes. Em algumas pessoas essa passagem não é realizada de forma satisfatória. Elas sofrem de alexitimia.

\section{Alexitimia}

Alexithymia é uma palavra com raízes gregas: a partícula $a$ tem um sentido de negação, de "falta ou ausência"; lex, significa "palavra"; e thymos é "emoção ou sentimento". Literalmente, alexitimia pode ser traduzida como sem palavras para sentimento. Quando trabalhavam em Boston, no Harvard Medical School, na década de 60, os psiquiatras John Nemiah e Peter Sifneos perceberam que alguns pacientes psicossomáticos mostravam grande dificuldade para falar sobre suas emoções e sentimentos, dando a impressão de não compreenderem o significado dessas palavras. Sifneos (1972) criou então a palavra alexitimia para explicar esse comportamento. Alexitimia é um construto que envolve três principais componentes: (a) uma grande dificuldade para usar uma linguagem apropriada para expressar e descrever sentimentos e diferenciá-los de sensações corporais; (b) uma capacidade de fantasiar e imaginar extremamente pobre; e (c) um estilo cognitivo utilitário, baseado no concreto e orientado externamente, também conhecido como pensamento operacional.

Todavia, esses comportamentos foram descritos na literatura especializada já há algum tempo. Em 1948, Jürgen Ruesch citou pacientes sem imaginação, que usavam ações e canais corporais para expressar suas emoções, eram falhos na comunicação afetiva e mostravam excessivo nível de conformidade social (citado em Bagby \& Taylor, 1999). Paul MacLean (1949) escreveu: "deve ser considerado que uma das notáveis observações sobre o paciente psicossomático é sua aparente inabilidade intelectual para verbalizar seus sentimentos" (p. 350). Em 1963, os psicanalistas franceses Marty e M'Usan mencionaram pacientes que eram incapazes de produzir fantasias e durante as entrevistas ficavam "presos" aos aspectos mundanos e operacionais de sua realidade, o que eles chamaram de "pensamento operacional" (Pensé Operatoire) (citado em Bagby \& Taylor, 1999). Contudo, coube a Sifneos $(1972,1973)$ a criação da palavra e do conceito de alexitimia.

Os alexitímicos têm sido descritos como robôs humanos (Sengupta \& Giri, 2009), portadores de uma espécie de analfabetismo emocional. Embora a alexitimia seja um construto clínico já testado, ela não constitui uma doença diagnosticada, mas sim um aspecto clínico associado à algum outro problema médico, tal como Desordem de Stress Pós Traumático, Anorexia Nervosa ou outra desordem psiquiátrica (Sengupta \& Giri, 2009; Taylor \& Bagby, 2002) . Todavia, existem evidências que possibilitam considerá-la como uma condição independente, uma disfunção afetivo-cognitiva, duplamente associada a alguma condição física-patológica e por danos à vida relacional do indivíduo (Sifneos, 2000), 
cuja incidência é estimada em $10 \%$ na população em geral (Aleman, 2005).

No Brasil a alexitimia ainda é relativamente desconhecida, mas no mundo ocidental esse é um construto que vem gerando um crescente número de pesquisas, existindo instrumentos de medição já traduzidos e adaptados para vários países (Wiethaeuper, Balbinotti, Pelisoli, \& Barbosa, 2005).

\section{Instrumentos de medição}

Wiethaeuper e cols. (2005) informam que, embora existam mais de seis instrumentos para identificar e medir a alexitimia, o TAS-20 (20-item Toronto Alexithymia Scale), desenvolvido por Bagby, Taylor e Parker (1994), é sem dúvida o mais conhecido e usado, tendo sido submetido a várias testagens e traduções. Existe uma versão portuguesa (Prazeres, Parker \& Taylor, 2000) e duas versões brasileiras (Wiethaeuper \& cols., 2005; Yoshida, 2000).

O TAS-20 é autoaplicável, e suas 20 questões são agrupadas em três fatores: o fator 1 indica que a pessoa tem dificuldade em identificar as próprias emoções e sentimentos; o fator 2 indica dificuldade em descrever essas emoções e sentimentos para os outros: a pessoa tem uma linguagem emocional pobre, confusa, mal utilizada; e o fator 3 indica um estilo de pensamento orientado para o exterior: questões operacionais do dia-a-dia dominam os pensamentos e atitudes dessa pessoa.

Para Taylor (2000), apesar do fator que efetuava a medição da capacidade imaginativa (de fantasiar e sonhar) ter sido eliminado na versão do TAS-20 (ele existia em versão anterior, o TAS-26, com 26 questões), a dificuldade em imaginar, de certa forma, está associada aos segundo e terceiro fatores dessa versão. Com efeito, a capacidade de imaginação usa tanto os sistemas cognitivos quanto os emocionais. Se há dificuldade na expressão consciente das emoções (dentre as quais, desejos, motivações), isso pode também indicar uma dificuldade em imaginar e fantasiar. Um pensamento operacional, em que a emoção não é conscientizada, dá às ações um caráter reativo, não direcionado para metas e objetivos desejados, os quais supõem a capacidade de imaginar e fantasiar.

Um segundo instrumento bem aceito é o BVAQ (Bermond-Vorst Alexithymia Questionnaire). Esse instrumento pretende identificar cinco fatores da alexitimia, os quais são descritos em inglês com as palavras emotionalizing, fantasizing, identifying, analyzing e verbalizing (Morera \& cols., 2005), e traduzidos para o português como segue:

- Emocionando-se: mede o nível no qual a pessoa é excitada por eventos emocionais. Exemplo de uma questão desse fator: "Quando algo inesperado acontece, eu permaneço calmo e imóvel";

- Fantasiando: mede a tendência da pessoa para ter "sonhos acordados", fantasias e projetos imaginados. Exemplo de uma questão: "eu tenho poucas fantasias e sonhos";

- Identificando: corresponde a habilidade pessoal para definir seu próprio estado emocional. Exemplo: "Quando estou tenso, permanece obscuro de qual sentimento essa tensão procede";

- Analisando: mede o interesse da pessoa em buscar fora de si mesma a fonte de suas reações emocionais. Exemplo: "raramente eu considero meus sentimentos";

- Verbalizando: mede a tendência ou capacidade da pessoa para descrever ou comunicar a própria emoção. Exemplo: "Eu acho difícil verbalizar meus sentimentos".

Existe uma versão portuguesa (de Portugal) desse instrumento, traduzido e testado por Ramiro Veríssimo, não publicada $^{5}$ até a data de elaboração deste trabalho. Um comunicado feito por esse autor num congresso está em Veríssimo (2005).

Todas as questões no BVAQ e TAS-20 estão numa escala Likert de cinco pontos, cujas respostas referem-se sempre à percepção da pessoa sobre seu comportamento em cada questão, variando de "concordo plenamente" a "discordo totalmente".

\section{Origens da alexitimia}

Não há consenso sobre o que causa a alexitimia. Existem os que a associam a algum trauma cerebral (Wood \& Willia$\mathrm{ms}, 2007$ ), a defeitos na formação neurológica (Aleman, 2005; Berthoz \& cols., 2002), a influências socioculturais (Kirmayer, 1987) e os que acreditam numa origem psicológica, como por exemplo, traumas na formação infanto-juvenil, ou mesmo mais tarde (Parker, Taylor \& Bagby, 1998).

Taylor (2000), um dos criadores do instrumento TAS-20, realizou uma revisão bibliográfica para avaliar o desenvolvimento da teoria e pesquisa sobre alexitimia, identificando uma proposta segundo a qual nos alexítimicos existiria um rompimento na comunicação entre os dois hemisférios cerebrais: ou seja, uma "comissurotomia funcional", refletida numa limitada capacidade de coordenar e integrar atividades inter-hemisféricas (Lumley \& Sielky, 2000), o que tem ressonância com propostas de Schore (2003a) para explicar outras desordens do fluxo emocional. Outra revisão foi realizada por Taibnia e Zaidel (2005), especificamente direcionada para avaliar evidências que confirmassem a proposta de Taylor. Os dois estudos são cautelosos em suas conclusões, indicando que permanecia a necessidade de confirmação direta e definitiva dessa proposta. Mas, em 2008, pesquisadores italianos realizaram uma pesquisa com o objetivo de buscar essa evidência direta da ocorrência de déficit na transferência inter-hemisférica entre os alexitímicos (Romei \& cols., 2008), encontrando suporte para essa hipótese.

Todavia, mesmo que alguma causa orgânica possa contribuir para a alexitimia, adotamos a perspectiva dos autores que propõem que ela é desenvolvida; isto é, ela surge a partir e durante as interações da pessoa com o ambiente ${ }^{6}$, princi-

5 Comunicação pessoal (e.mail) em 20.05.2008.

6 Por exemplo, adultos que sofrem de Distúrbio Pós-Traumático desenvolvem alexitimia, como em traumas de guerra e de campos de concentração (Yehuda \& cols., 2004). 
palmente no seu período de formação. Dito de outra forma, o alexitímico, segundo essa proposta, não tem um problema anatômico ou de arquitetura cerebral, mas um problema de funcionamento cerebral, uma disfunção cerebral aprendida, como acontece, por exemplo, com outras desordens afetivas (Schore, 2003a, 2003b).

O cérebro não está desenvolvido por igual no nascimento e são necessários muitos anos de desenvolvimento pós-natal para que uma pessoa madura venha a se formar Esses anos exigem a participação de outras pessoas na formação do futuro adulto, as quais ajudam a criança a aprender a identificar e regular suas emoções. Isso é primariamente executado pela mãe ou pela pessoa que desempenhe esse papel, a qual necessita estar "sintonizada" com as necessidades da criança, conforme atestam recentes pesquisas (Hane \& Fox, 2006). Para Schore (1994), esse processo é biopsicosocial: "A tese central ... é que o ambiente social inicial, mediado pelos cuidadores primários, diretamente influencia a evolução de estruturas cerebrais que são responsáveis pelo futuro desenvolvimento socioemocional da criança" (p. 62). Bagby e Taylor (1999) dizem que quando o cuidador inicial é indisponível ou não está sintonizado com as necessidades da criança, ela "provavelmente manifestará anormalidades em seu desenvolvimento afetivo e regulação afetiva" (p. 41). Um caso notório dessa situação é o das crianças romenas, descobertas após a ruptura da URSS: criadas em orfanatos sem cuidadores adequados, elas foram incapazes de desenvolver laços emocionais com os que posteriormente as adotaram (Begley, 2007/2008).

$\mathrm{O}$ cérebro de um recém nascido pesa algo em torno de $350 \mathrm{~g}$, enquanto o cérebro adulto pesa em média de 1300 a 1500 g. Segundo Rose (2005/2006), com seis anos o cérebro humano alcança $90 \%$ de seu peso adulto e $95 \%$ em torno dos 10 anos. Durante esse desenvolvimento, o cérebro é preparado para reagir ao contexto, adquirindo grande plasticidade, modificando sua estrutura e conectividade em resposta à experiência: "As conexões sinápticas são moldadas, algumas delas aguçadas e outras podadas, de modo a identificar e reagir a aspectos relevantes do mundo exterior" (Rose, 2005/2006, p. 131). Assim, várias das conexões (ou circuitos) neuronais, necessárias para uma vida adulta normal, precisam ser aprendidas pelo ser humano durante sua infância e puberdade, à medida que o ambiente propicie experiências adequadas. Dentre essas conexões estão as que integram as áreas subcorticais e pré-frontais, necessárias para que a pessoa tome consciência de suas emoções e desenvolva sentimentos.

A necessidade de cuidados, que a criança tem, não é uma necessidade ditada pelas convenções sociais, mas desenvolvida durante a evolução da espécie. Da mesma forma que existe o impulso genético para gerar e criar, da mulher/mãe, existe a necessidade genética da criança em ser "criada", isto é, em ser cuidada durante a fase em que ainda não pode cuidar de si mesma, por ser um ser incompleto. A ausência ou negligência nesses cuidados prejudica o desenvolvimento social e emotivo da criança (Begley, 2007/2008; Schore, 2003a).

Um dos possíveis resultados dessa negligência é a alexitimia. A criança não só não aprende a desenvolver sentimentos conscientes, como aprende a evitá-los: ela aprende a evitar a conscientização das emoções, a partir da emoção negativa de dor, consequência de sua necessidade não atendida, da negli- gência de que foi objeto, registrada na expressão "nunca vou amar alguém, para não ter que sofrer", dita ao autor deste artigo por um alexitímico adulto. Nesse caso, a alexitimia pode ser também considerada como uma característica de personalidade, aprendida e derivada de um estilo de enfrentamento emocional (Helmes, E., MaNeill, P., Holden, R., Jackson, C., 2008; Yoshida, 2005), desenvolvido durante o processo de formação do alexitímico. Ao invés de aprender a perceber e regular suas emoções de forma positiva, criando "bons sentimentos", a criança aprende a evitar as conexões sinápticas desse fluxo regular, desenvolvendo um fluxo deficiente que vai trazer reflexos negativos para sua saúde e relacionamentos, na vida adulta.

\section{Alexitimia, problemas relacionais e psicossomáticos}

As características centrais da espécie humana são resultados dos processos evolucionários inerentes à Vida. Como produtos da evolução, as emoções existem porque favorecem o ser vivo em suas relações com o ambiente. Se a emoção não contribuísse para a sobrevivência, teria sido eliminada do repertório das experiências de vida (Candland, 2003). A experiência da emoção, desse ponto de vista, é uma característica que foi desenvolvida evolucionariamente, tem uma natureza biológica.

Por outro lado, o ser humano vive imerso numa cultura e toda cultura possui uma rica linguagem, rituais e símbolos para comunicar emoções, um elenco de palavras, expressões físicas e simbólicas, que garantem eloquência quando se quer sensibilizar alguém ou solicitar ajuda. Chamar a atenção do outro por meio de uma expressão verbal ou corporal que pareça a quem a ouve/vê uma condição dolorosa ou de desconforto, é uma forma de mostrar ao outro que alguma coisa está errada. Se uma pessoa diz, verbal e/ou simbolicamente, que gosta da presença de alguém, esse alguém terá uma tendência de sentir-se bem na presença do outro. Isso gera uma "via de mão dupla", desenvolvendo relacionamentos. Da mesma forma, se alguém demonstra insatisfação, ou mesmo uma simples ausência de satisfação pela presença de outra pessoa, a reação atitudinal desse outro será de defesa e de afastamento. Isso gera um desconforto quando os dois se encontram. No mínimo, isso inibe e inviabiliza um relacionamento. Nessa abordagem, a expressão consciente da emoção, necessária para que haja o desenvolvimento do sentimento, é um aprendizado, com uma forte conotação de aprendizado social (Kirmayer, 1987), fundamental para formar um relacionamento.

Nossa cultura incentiva e apoia a expressão de sentimentos pessoais, como forma de comunicação nos relacionamentos sociais. Mas o receptor e o emissor do sinal comunicacional necessitam dispor das mesmas chaves interpretativas, moldadas pela cultura, pela educação e experiências pessoais, para que emissor e receptor codifiquem e decodifiquem os sinais de forma adequada, realizando a comunicação. Isso significa que um relacionamento entre alexitímico e não alexitímico será uma fonte de conflitos, porque o universo simbólico-emocional de cada um não é compreensível para o outro: eles não possuem a chave interpretativa para decodificar a mensagem um do outro. Desse 
ponto de vista, a alexitimia é uma falha no desenvolvimento social do individuo, que impede a construção de um mundo simbólico a ser socialmente compartilhado (Kirmayer, 1987).

A linguagem usada por uma pessoa em suas interações sociais diárias, seus sonhos, fantasias, choro, jogos, sorrisos e mecanismos de defesa e de aproximação (partilha, con-vivência, empatia), desempenham importantes papéis na regulação das emoções, estabelecendo o tônus de um relacionamento. Ela oferece suporte para aproximar ou afastar pessoas. Incapaz de identificar seus estados afetivos, o alexitímico não só é inábil em refletir sobre e regular suas emoções, mas também se comunica emocionalmente de forma muito pobre com as outras pessoas, falhando em atrair outros para receber ou dar ajuda e conforto. Por sua vez, a falta de compartilhamento emocional contribui para dificultar o aprendizado da identificação das emoções, instalando um círculo vicioso. Pessoas que se mostram incapazes de falar sobre suas emoções e fantasias frequentemente sofrem de sintomas psicossomáticos e problemas relacionais. Pesquisas mostram que alexitímicos têm uma propensão maior para permanecerem solteiros que não alexitímicos e estão expostos a maior risco de morte por doença (Spitzer, Siebel-Jurges, Barnow, Grabe, \& Freyberger, 2005).

Lumley, Ovies, Stettner, Wehmer e Lakey (1996) realizaram uma série de pesquisas, objetivando identificar a associação entre alexitimia, qualidade do suporte social percebido e doenças de natureza psicossomática. Os resultados alcançados indicaram que os alexitímicos têm fraca percepção de suporte social, pequena rede social em face de fraca habilidade social e propensão a desenvolverem problemas psicossomáticos. Grabe, Spitzer e Freyberger (2004) testaram e confirmaram a hipótese de que a dificuldade de identificar emoções, prevista na alexitimia, é altamente preditiva de um amplo repertório de estados psicopatológicos, particularmente a somatização. Em contraste, pensamento orientado externamente (pensamento operatório) quase não tem correlação com esses estados de somatização. Achados semelhantes foram encontrados por Lumley e cols. (1996). Esses achados podem ser uma pista indicando que o pensamento operatório não é fator direto na causa de problemas de saúde física, mas pode afetar os relacionamentos por ser um dos elementos que demonstrará ao outro a ausência da intimidade subjetiva.

Os alexitímicos são pessoas vulneráveis a desenvolverem alguma desordem de personalidade, como narcisismo ou TOC (Bach, 1994), e/ou doenças psicossomáticas (Bach, Bohmer \& Nutzinger, 1994), como a hipertensão (Jula, Salminem \& Saarijarvi, 1999). A alexitimia também foi associada ao câncer (Nada, 1997), desordens alimentares (Taylor, Parker, Bagby \& Boukes 1999), uso abusivo de drogas (Caldas, 1999), depressão e alcoolismo (Maciel \& Yoshida, 2006), e outras desordens (Bankier, Aigner \& Bach, 2001) relacionadas no Manual de Diagnóstico e Estatística das Perturbações Mentais (DSM-IV) da Associação Psiquiátrica Americana. Também o processo decisório do alexitímico é limitado. Decidir significa escolher entre opções e essa escolha se ampara em emoções conscientizadas (Bechara, Damásio \& Damásio 2000) ): motivações (desejos) e metas (futuro imaginado). O alexitímico, face à sua pobreza imaginativa, tem dificuldades de tomar decisões porque "não sabe o que quer".
Não sendo uma doença, no sentido físico do termo, e por suas características, que dirige o foco da atenção da pessoa para o externo, o alexitímico não se percebe desajustado: quase sempre resiste a um tratamento. A terapia convencional (apoiada na verbalização de emoções) tem pouco ou nenhum efeito sobre ele. Mas, considerando a etiologia de aprendizado aqui atribuída à alexitimia e à neuroplasticidade que caracteriza o cérebro humano (Begley, 2007/2008; Schore, 2003b), pode-se prever que terapias específicas, baseadas em processos de reeducação e reaprendizagem emocional venham a ser desenvolvidas para corrigir essa deficiência funcional cerebral aprendida.

\section{Fluxo das emoções e regulação emocional}

Para Kirmayer, (1987), as emoções no alexítimico são "hiposimbolizada, ou, mais propriamente, hipocognizadas? tanto que são expressas de forma não modulada e como resposta predominantemente vaga e indiferenciada" (p. 121). Ou seja, é o caminho que a energia emocional percorre, seu circuito neuronal sináptico, aqui chamado de "fluxo emocional", que pode gerar, ou não, uma condição alexitímica. Usando as ideias de LeDoux e Damásio: no fluxo emocional "regular", os circuitos neuronais responsáveis pela emoção alcançam regiões pré-frontais do cérebro, as quais permitem a pessoa percebê-la e expressá-la conscientemente. No fluxo emocional alexitímico, um fluxo "deficiente", os circuitos neuronais não alcançam essas regiões de forma adequada. Aqui se pode interpretar que a resposta emocional hipocognizada, vaga e indiferenciada, indica um fluxo que no máximo realiza aquilo que LeDoux $(2000,2007)$ chama de processos cognitivos inconscientes e Damásio (1999/2000) chama de sentimentos inconscientes. Na ocorrência desse fluxo deficiente, há ausência de conscientização da emoção (os processos pré-frontais não ocorrem de forma plena), caracterizando a alexitimia. Grotstein (1999) diz que o indivíduo alexitímico "revela uma incapacidade de processamento cognitivo saudável" (p. XI).

O fluxo regular aqui não implica necessariamente emoções positivas. Esse mesmo fluxo pode existir para emoções negativas e gerar sentimentos negativos. O fluxo é regular no sentido de que percorre o caminho que tem que percorrer: ativação neurofisiológica e processos subcorticais inconscientes, seguidos de processos pré-frontais conscientes. Se sentimentos negativos (e.g., a conscientização da raiva gerando ressentimento consciente) forem cultivados e daí a pessoa desenvolver sintomas psicossomáticos, isso não será devido à alexitimia, posto que ela não existe.

Nesse exemplo, a regulação da emoção, pela pessoa, é que não foi adequada, segundo as convenções sociais que perpassam por nossa cultura. Regulação emocional significa a forma como a pessoa experimenta e expressa a emoção: de forma amortecida, minimizada ou de forma intensificada, cultivada (Gross \& Thompson, 2006), permitindo à pessoa desenvolver ou não seus sentimentos. A regulação da emoção

7 A palavra original em inglês é "hypocognized", sem tradução direta para o português. Para manter a ideia do autor, a palavra foi traduzida para hipocognizada, a qual, acreditamos, é de fácil compreensão. 
integra a regulação biológica do organismo, constituindo um aspecto essencial para orientar um comportamento adaptativo adequado (Bagby \& Taylor, 1999; Damásio, 1995), incluindo o desenvolvimento da empatia (Decety \& Moriguchi, 2007). Um fluxo regular e uma adequada regulação da energia emocional permitirão à pessoa usufruir de emoções e sentimentos positivos e precaver-se contra ameaças a partir de emoções negativas (e.g., medo); no fluxo deficiente, a energia permanece no corpo de forma não regulada, podendo ocasionar danos ao corpo e relacionamentos.

Nesse caso, um relacionamento estabelecido pelo alexitímico tem uma natureza mais superficial, podendo gerar as sensações emocionais vagas e indiferenciadas sugeridas por Kirmayer, insuficientes para sustentar um relacionamento mais profundo. Sem a percepção consciente das emoções subjacentes a essas sensações, os sentimentos não são expressos, portanto, não podem ser cultivados nem desenvolvidos. Isso acaba por gerar estados de saúde física e mental problemáticos, justificando as palavras de Panksepp (que usa o conceito de afeto, para reunir emoções e sentimentos):

Sem afeto, podemos nos sentir sem vida; sem afetos positivos, existem poucas razões para viver... sem afetos, não há alegria nem dor. Afeto é a fonte de toda intimidade... encorajando as pessoas a cavar profundamente em sua "alma" biológica-para encontrar empatia, comunicar seus interesses sinceramente e esperar reciprocidade para sua profundidade de sentimento. (2008, p. 47)

A impossibilidade de encontrar empatia e expressar os interesses emocionais, característica do alexitímico, impede a via de mão dupla dos relacionamentos, dificultando ou mesmo inviabilizando a reciprocidade referida.

\section{Considerações Finais}

Neste artigo apresentamos as ideias de LeDoux e Damásio sobre os processos neurais responsáveis pela emoção e pelo sentimento. Vimos que os processos emocionais necessitam de uma sequência para se tornarem processos de sentimentos e que esta sequência não ocorre no alexitímico. Não afirmamos que o alexitímico não tenha emoções: para o autor deste trabalho, os circuitos neurais reconhecidos por LeDoux e Damásio para as emoções, no alexitímico estão intactas. Todavia, o alexitímico não consegue realizar a passagem emoção - sentimento; nele, o circuito neural que permite a autoconsciência emocional (percepção consciente das sensações subjetivas que acompanham as emoções) não é completado de forma satisfatória, resultando num circuito que não permite a regulação (experienciação e expressão) emocional adequada. Esse circuito deficiente impede a geração do sentimento consciente, um processo cognitivoexperiencial. Não havendo geração de sentimento, não há também a possibilidade de seu cultivo. Instala-se o círculo vicioso referido.

Entretanto, essas conclusões são inferências baseadas em dados que foram gerados para outras finalidades, e não para atender aos nossos objetivos específicos. Esse é um limite deste trabalho, indicativo da necessidade de mais pesquisas sobre o tema.
Os estímulos que chegam ao cérebro humano são processados pelos sentidos e adquirem um significado. Esse significado tem sempre um componente emocional: gosto disso? É bom para mim? Mesmo a indiferença corresponde a um julgamento emocional, que pode mudar a qualquer instante. No ambiente de que participa, o ser humano transmite esses significados por meio de elementos adequados à sua espécie, cultura e experiências. Esse significado pode ser consciente: a pessoa pode saber qual emoção está sentindo e assim cultivar, ou transformar, isso que está sentindo.

Saber o que se está sentindo exige um processo de aprendizagem, que o ser humano desenvolve desde seu nascimento, a partir de aparatos cerebrais só disponíveis para os humanos, e de ambientes adequados para a aprendizagem. Ambiente no qual as emoções são livremente expressadas gera um clima de confiança e confidência, de companheirismo, que alimenta a expressão de emoções positivas e cria sentimentos positivos. Isso gera um "círculo virtuoso", em face da passagem dos circuitos neuronais da emoção para os circuitos neuronais do sentimento. A deficiência nesses dois pontos, a autoconsciência emocional e a passagem emoção-sentimento foram apontadas como sendo causadoras de alexitimia; todavia, isso necessita de pesquisas adicionais, para confirmação ou refutação. Por outro lado, acreditamos que essas pesquisas poderão também indicar caminhos para o desenvolvimento de terapias com as quais o alexitímico possa aprender a desenvolver o círculo virtuoso.

\section{Referências}

Aleman, A. (2005). Feelings you can't imagine: Towards a cognitive neuroscience of alexithymia. Trends in Cognitive Sciences, 9, 553-555.

Bach, M. (1994). Alexithymia: Relationship to personality disorders. Comprehensive Psychiatry, 35, 239-243.

Bach, M., Bohmer, F., \& D. Nutzinger (1994). Alexithymia and somatization: Relationship to DSM IV-R diagnoses. Journal of Psychosomatics Research, 38, 529-538.

Bagby, M., \& Taylor, G. (1999). Affect dysregulation and alexithymia. In G. Taylor \& M. Bagby (Orgs.), Disorders of affect regulation (pp. 7-25). Cambridge: Cambridge University.

Bagby, R., Taylor, G., \& Parker, J. (1994). The Twenty-Item Toronto Alexithymia Scale. Journal of Psychosomatic Research, 38, 23-40.

Bankier, B, Aigner, M., \& Bach, M. (2001). Alexithymia in DSM IV Disorder - Comparative evaluation of somatoform disorder, panic disorder, obsessive-compulsive disorder, and depression. Psychosomatics, 42, 235-240.

Barret, L. (2006). Solving the emotion paradox: Categorization and the experience of emotion. Personality and Social Psychology Review, 10, 20-46.

Baumeister, R., Vohs, K., DeWall, C., \& Zhang, L., (2007). How emotion shapes behaviour: Feedback, anticipation, and reflection, rather than direct causation. Personality and Social Psychology Review, 11, 167-203.

Begley, S. (2008). Treine a mente, mude o cérebro (B. Casotti, Trad.). Rio de Janeiro: Objetiva. (Trabalho original publicado em 2007)

Bechara, A., Damasio, H., \& Damasio, A. (2000). Emotion, decision making and the orbitofrontal cortex. Cerebral Cortex, 10, 295-307. 
Berthoz, B., Artiges, E., de Moortele, P. F., Poline, J. B., Rouquette, S., Consoli, S., \& Martinot, J. (2002). Effect of impaired recognition and expression of emotions on frontocingulate cortices: An fMRI study of men with alexithymia. American Journal of Psychiatry, 159, 961-967.

Caldas, N. (1999). Avaliação da alexitimia em usuários de drogas em centro de tratamento na cidade do Rio de Janeiro. Dissertação de Mestrado, Escola Nacional de Saúde Pública, Rio de Janeiro.

Candland, D. (2003). The persistents problems of emotions. Em D. Candland, J. Fell, E. Keen, A. Leshner, R. Plutchik, \& R. Tarpy (Orgs.), Emotions (pp. 01-84). Nova York: Authors Choice.

Damásio, A. (1995) Toward a neurobiology of emotions and feeling: Operational concepts and hypotheses. The Neuroscientist, $1,19-25$

Damásio, A. (1996). O erro de Descartes. Emoção, razão e o cérebro humano (D. Vicente \& G. Segurado, Trad.). São Paulo: Cia das Letras. (Trabalho original publicado em 1994)

Damásio, A. (2000). O mistério da consciência (L. T. Mota, Trad.). São Paulo: Cia. das Letras. (Trabalho original publicado em 1999)

Decety, J., \& Moriguchi, Y. (2007) The emphatic brain and its dysfunction in psychiatric populations: Implications for intervention across different clinical conditions. ByoPsychoSocial Medicine, 1, 22.

Gazzaniga, M., \& Heatherton, T. (2005). Ciência psicológica (M. A. V. Veronese, Trad). Porto Alegre: Artmed. (Trabalho original publicado em 2003)

Grabe, H., Spitzer, C., \& Freyberger, H. (2004). Alexithymia and personality in relation to dimensions of psychopathology. American Journal of Psychiatry, 161, 1299-1301.

Gross, J., \& Thompson, R. (2006). Emotion regulation: Conceptual foundations. Em J. J. Gross (Org.), Handbook of emotion regulation (pp. 3-22) New York: Guilford.

Grotstein, J. (1999). Alexithymia: The exception that proves the rule of the unusual significance of the affects. Em J. Graeme, R. Taylor \& M. Bagby (Orgs.), Disorders of affect regulation (pp. XI-XVIII). Cambridge: Cambridge University.

Hane, A., \& Fox, N. (2006). Ordinary variations in maternal caregiving influence infants' stress reactivity. Psychological Science, 17, 550-556.

Helmes, E., McNeill, P., Holden, R., \& Jackson, C. (2008). The construct of alexithymia: Associations with defense mechanisms. Journal of Clinical Psychology, 64, 318-331.

Jula, A., Salminem, J., \& Saarijarvi, S. (1999). Alexithymia: A facet of essential hypertension. Journal of the American Heart Association, 33, 1057-1061.

Kirmayer, L. (1987). Languages of suffering healing: Alexithymia as a social and cultural process. Transcultural Psychiatry, 24, 119-136.

Kleinginna, P. R., \& Kleinginna, A. M. (1981). A categorized list of emotion definitions with suggestions for a consensual definition. Motivation and Emotion, 5, 345-379.

LeDoux, J. (1998). O cérebro emocional. Os misteriosos alicerces da vida emocional (T. B. Santos, Trad.). Rio de Janeiro: Objetiva. (Trabalho original publicado em 1996)

LeDoux, J. (2000). Emotional circuits in the brain. Annual Reviews in Neuroscience, 23, 155-184.

LeDoux, J. (2007). Unconscious and conscious contributions to the emotions and cognitive aspects of emotions: A comment on Scherer's view of what an emotion is. Social Science Information, 46, 395-407.
Lumley, M., Ovies. T., Stettner, L., Wehmer, F., \& Lakey, B. (1996). Alexithymia, social support and health problems. Journal of Psychosomatic Research, 41, 519-530.

Lumley, M., \& Sielky, J. (2000). Alexithymia, gender and hemispheric functioning. Compreensive Psychiatry, 41, 352359.

Maciel, M., \& Yoshida, E. (2006). Avaliação de alexitimia, neuroticismo e depressão em dependentes de álcool. Avaliação Psicológica. , 5, 43-54.

MacLean, P. (1949). Psychosomatic disease and the "visceral brain". Journal of Psychosomatic Medicine, 11, 338-353.

Morera, O., Culhane, S., Watson, P., \& Skees, M. (2005). Assessing the realibility and validity of the Bermond-Vorst Alexithymia Questionnaire among U.S. Anglo and U.S. Hispanic samples. Journal of Psychosomatic Research, 58, 289-298.

Nada, P. (1997). Alexithymia and cancer. Japanese Journal of Psychosomatic Medicine, 37, 585-588.

Panksepp, J. (2008). The affective brain and core consciousness: How does neural activity generate emotional feelings? Em M. Lewis, J. Haviland-Jones \& L. Barrett (Orgs.), Handbook of emotion (pp. 47-67). New York: Guilford.

Parker, J., Taylor, G., \& Bagby, M. (1998). Alexithymia: Relationship with ego-defense and coping style. Compreensive Psychiatry, 39, 91-98.

Prazeres, N., Parker, D., \& Taylor, J. (2000). Adaptação portuguesa da Escala de Alexitimia de Toronto de 20 Itens (TAS-20). Revista Oficial de La Associacion Iberoamericana de Diagnóstico y Evaluacion Psicológica, 9, 9-21

Romei, V., DeGennaro, L., Fratello, F., Curcio, G., Ferrara, M., Pascual-Leone, A., \& Bertini, M. (2008). Interhemispheric transfer deficit in alexithymia: A transcranial magnetic stimulation study. Psychotherapy and Psichossomatics, 77, 175-181.

Rose, S. (2006). O cérebro no século XXI. Como entender, manipular e desenvolver a mente (H. Londres, Trad.). São Paulo: Globo. (Trabalho original publicado em 2005)

Scherer, K. (2005). What are emotions? And how can they be measured? Social Science Information, 44, 695-729.

Schore, A. (1994). Affect regulation and the origin of the self. New York: Lawrence Erlbaum.

Schore, A. (2003a). Affect dysregulation and disorders of the self. New York: Norton \& Company.

Schore, A. (2003b). Affect regulation and the repair of the self. New York: Norton \& Company.

Sengupta, A., \& Giri, V. (2009) Alexithymia and managerial styles: Implications in Indian organizations. Journal of the Indian Academy of Applied Psychology, 35, 71-77.

Sifneos, P. (1972). Short-term psychotherapy and emotional crisis. Boston: Harvard University.

Sifneos, P. (1973). The prevalence of alexithymic characteristics in psychossomatics patients. Psychotherapy and Psychossomatics, 22, 255-262

Sifneos, P. (2000). Alexithymia, clinical issues, politics and crime. Psychotherapy and Psychosomatics, 69, 113-116.

Spitzer, C., Siebel-Jurges, U., Barnow, S., Grabe, H. J., \& Freyberger, H. (2005). Alexithymia and interpersonal problems. Psychoterapy and Psychossomatics, 74, 240-246.

Taibnia, G., \& Zaidel, E. (2005). Alexithymia, interhemispheric transfer, and right hemispheric specialization: A critical review. Psychoterapy and Psychossomatics, 74, 81-92. 
Taylor, G. (2000). Recent development in alexithymia theory and research. The Canadian Journal of Psychiatry, 45, 134-142.

Taylor, G., Parker, J., Bagby, M., \& Boukes, M. (1999). Relationship between alexithymia and psychological characteristics associated with eating disorders. Journal of Psychosomatic Research, 41, 561-568.

Veríssimo, R. (2005). The assessment of alexithymia: A psychometric study comparing two self-report measurements. Journal of Psychosomatic Research, 58, 14-15.

Wiethaeuper, D., Balbinotti, M., Pelisoli, C., \& Barbosa, M. (2005). Estudos da consistência interna e fatorial confirmatório da Escala Toronto de Alexitimia-20 (ETA-20). Revista Interamericana de Psicologia / Interamerican Journal of Psychology, 39, 221-230. Retirado em outubro/2007, de http://www.psicorip.org/Resumos/ PerP/RIP/RIP036a0/RIP03924.pdf .

Wood, R., \& Williams, C. (2007). Neuropsychological correlates of organic alexithymia. Journal of the International Neuropsychological Society, 13, 471-479.
Yehuda, R., Steiner, A., Kahana, B., Binder-Brynes, K., Southwick, S., Zemelman, S., \& Giller, E. (2004). Alexithymia in holocaust survivors with and without PTSD. Journal of Traumatic Stress, 10, 93-100.

Yoshida, E. M. P. (2000). Toronto Alexthymia Scale-TAS: precisão e validade da versão em português. Psicologia: Teoria e Prática, 2, 59-74.

Yoshida, E. M. P. (2005). Stress e alexitimia [Resumo]. Em Portal da Educação Física (Org.), Anais do II Congresso Brasileiro de Stress (p. 96). São Paulo.

Recebido em 16.09.08

Primeira decisão editorial em 28.10.09

Versão final em 06.11.09

Aceito em 09.12.09 